\title{
Análisis de los periódicos infantiles en la Biblioteca del Museo del Romanticismo. Documentación gráfica en la prensa ilustrada
}

\author{
MARÍA OLIVERA ZALDUA \\ Departamento de Biblioteconomía y Documentación \\ Universidad Complutense de Madrid \\ JUAN MiguEL SÁNCHEZ VIGIL \\ Departamento de Biblioteconomía y Documentación \\ Universidad Complutense de Madrid \\ PALOMA DORADO PÉREZ \\ Biblioteca del Museo del Romanticismo
}

Recibido: $07 / 03 / 2013$

Aceptado: 18/03/2013

\begin{abstract}
RESUMEN
La información en la prensa ilustrada es una de las principales fuentes documentales, por lo que su recuperación es fundamental para los investigadores. La Biblioteca del Museo del Romanticismo cuenta con seis publicaciones periódicas infantiles, adquiridas recientemente, que conforman un importante corpus sobre la materia, periódicos editados en la segunda parte del siglo XIX de cuyo análisis resultan aportaciones generales en varios campos: historia de la prensa ilustrada, publicaciones periódicas infantiles, educación decimonónica, uso y aplicación de las imágenes y documentación gráfica, además de temas específicos como literatura, historia, geografía, viajes, etc. Se realiza el primer estudio en forma y fondo de dichas publicaciones, y se recupera la información sobre autores, materias e ilustraciones con el objetivo de ponerlos en valor y difundirlos.

Palabras clave: Biblioteca del Museo del Romanticismo, documentación gráfica, prensa infantil, publicaciones periódicas ilustradas, El Faro de la niñez, El Mentor de la infancia, La Ilustración de la infancia, La Niñez, La Semaine des enfants y Museo de familias

Analysis of the children's periodicals in the Museo del Romanticismo Library. Information retrieval and graphic documentation in the illustrated press
\end{abstract}

\begin{abstract}
The information in the illustrated press is one of the leading documentary sources and so its retrieval is fundamental to researchers. The Museo del Romanticismo Library has six children's periodical publications, acquired recently, which make up an important corpus on the matter. The analysis of these periodicals published in the second part of the $19^{\text {th }}$ century will result in valuable contributions to a variety of fields: the history of illustrated press, periodic children's publications, nineteenth century education, use and application of images and graphic documentation, as well as to specific areas such as literature, history, geography, travel, etc. An in-depth study is initially carried out on these publications and the information on authors, subjects and illustrations are retrieved in order to highlight and promote them.

Keywords: Museo del Romanticismo Library, graphic documentation, children's publications, illustrated periodicals, El Faro de la niñez, El Mentor de la infancia, La Ilustración de la infancia, La Niñez, La Semaine des enfants and Museo de familias.
\end{abstract}




\section{INTRODUCCIÓN}

La demanda del investigador en las bibliotecas especializadas requiere de acciones específicas por parte de los profesionales de la documentación, que deben responder a nuevos retos. Las bibliotecas de los museos son paradigma en este sentido, por tratarse de centros con fondos especializados cuya difusión se canaliza a través de la Red de Bibliotecas de Museos (Bimus, 2012). Entre dichos centros se encuentra la Biblioteca del Museo del Romanticismo con una colección histórica que requiere de especial atención en el tratamiento documental (Dorado-Pérez, 2012). Tal es el caso de las seis publicaciones periódicas infantiles que conserva y que aquí se estudian, de excepcional interés por su valor como prensa ilustrada y por su influencia en el cambio educativo que se produjo durante el siglo XIX. Los nuevos métodos de estudio nos posibilitan la profundización en la recuperación de la información, así como en su análisis cuantitativo y cualitativo (Martínez Comeche, 2011).

Sobre las publicaciones periódicas ilustradas se han realizado estudios de comunicación generales (Sánchez-Vigil, 2008; Trenc-Ballester, 1996) y específicos (Cuadrado, 2000; Altarriba, 2001 y Chivelet, 2009), y también desde la literatura (Escarpit, 1986) o la educación (Ameijeiras, 1991; Palenque, 1998; Checa, 2002). La primera publicación periódica infantil a la que nos referimos en este artículo es Museo de familias (1838-1841), de contenidos moralizantes, con profusión de ilustraciones e interés en el público infantil y juvenil como se explica en el prólogo: "Es también el muchacho aprendiz, para quien este libro vendrá a ser un recreo instructivo y quizás un freno moral". Obviamente, no se trata de una publicación infantil pero sí de una de las primeras con contenidos expresamente dedicados a niños y jóvenes. En la primera mitad del XIX surgieron además tres de los periódicos que se analizan: El Mentor de la infancia (1843-1845), El Faro de la niñez (1849-1851) y el semanario francés La Semaine des enfants (1857-1875). Durante la Restauración se publicaron las otras dos que estudiamos: La Ilustración de la infancia (1877-1879) y La Niñez: Revista de educación y recreo (1879-1882).

Es objeto de esta investigación analizar los seis periódicos en forma y fondo, con el fin de recuperar su información para aportar nuevos datos a la historia de la prensa ilustrada, a los estudios sobre las publicaciones infantiles y a la documentación gráfica. Se pretende también conocer los principales escritores e ilustradores que colaboraron en ellas y, en relación con las ilustraciones, valorar sus contenidos, cuantificarlos y establecer su temática, por tratarse de una gran fuente de información libre de derechos de autor. 


\section{METODOLOGÍA}

El método ha partido de la revisión de la bibliografía general y específica, con el fin de situar las publicaciones en el contexto de la prensa de la época, ya que ninguno de los periódicos analizados ha sido estudiado con anterioridad ni en fondo ni en forma. Las fuentes son las publicaciones originales, encuadernadas en 20 volúmenes que se han revisado exhaustivamente. Se han consultado también las únicas dos revistas digitalizadas: Museo de familias (Hemeroteca Digital de la Biblioteca Nacional), y Semaine des enfants (Biblioteca Digital Gallica de la Bibliothèque National de París).

Con el fin de conocer la existencia de ejemplares en otros centros de documentación, se han realizado búsquedas en Biblioteca Nacional, Catálogo Colectivo de Publicaciones Periódicas, Red de Bibliotecas Universitarias (Rebiun), Hemeroteca Municipal de Madrid y Prensa Histórica del Ministerio de Educación, Cultura y Deporte.

Para recuperar la información se ha diseñado una base de datos con campos sobre títulos, volúmenes, formatos, periodicidad, años de publicación, editores, directores e impresores. Asimismo se han abierto campos para obtener las principales materias, los escritores, dibujantes y grabadores. Se han cuantificado y valorado las ilustraciones, estableciendo una relación con las materias para conocer los temas más ilustrados.

\section{LOS PERIÓDICOS INFANTILES EN LA BIBLIOTECA DEL MUSEO DEL ROMANTICISMO}

La biblioteca del Museo del Romanticismo, de titularidad estatal y dependiente del Ministerio de Educación, Cultura y Deporte, fue creada en el primer cuarto del siglo XX por Benigno de la Vega Inclán (Menéndez-Robles, 2006), quien formó la colección con obras adquiridas a libreros y anticuarios, más duplicados de la Biblioteca de Palacio regalados por Alfonso XIII. Mariano Rodríguez de Rivas, director del Museo entre 1946 y 1958, impulsó la biblioteca, aumentando el volumen bibliográfico. En la actualidad consta de unos 14.500 volúmenes, de los que 5.000 son fondo antiguo, con una importante colección de publicaciones periódicas compuesta por unos 300 títulos, la mitad del siglo XIX, entre ellos los seis infantiles que se estudian (Tabla 1). 


\begin{tabular}{|c|c|c|c|}
\hline & PUBLICACIONES & FECHAS & VOLS. DEL MUSEO \\
\hline $\begin{array}{l}\text { Título } \\
\text { Subtitulo }\end{array}$ & $\begin{array}{l}\text { Museo de familias } \\
\text { (no tiene) }\end{array}$ & $\begin{array}{l}1838- \\
1841\end{array}$ & $1838-1840$ (3 vols.) \\
\hline $\begin{array}{l}\text { Título } \\
\text { Subtítulo }\end{array}$ & $\begin{array}{l}\text { El Mentor de la infancia } \\
\text { Periódico dedicado exclusivamente a la } \\
\text { juventud } \\
\text { Periódico de niños por Sociedad de } \\
\text { padres de familia }\end{array}$ & $\begin{array}{l}1843- \\
1845\end{array}$ & 1845 (1 vol.) \\
\hline $\begin{array}{l}\text { Título } \\
\text { Subtítulo }\end{array}$ & $\begin{array}{l}\text { El Faro de la niñez } \\
\text { Periódico de la Educación oficial de la } \\
\text { Sociedad de Socorros Mutuos de } \\
\text { Instrucción Pública }\end{array}$ & $\begin{array}{l}1849- \\
1851\end{array}$ & $\begin{array}{l}1849 \text { oct-sep } 1850 \\
(1 \text { vol.) } \\
1850 \text { ost-jun } 1851 \\
(1 \text { vol.) }\end{array}$ \\
\hline $\begin{array}{l}\text { Títule } \\
\text { Subtitule }\end{array}$ & $\begin{array}{l}\text { La Semaine des enfants } \\
\text { Magasin d'images et lectures amusante } \\
\text { et instructives }\end{array}$ & $\begin{array}{l}1857- \\
1875\end{array}$ & $\begin{array}{l}1861 \text { (1 vol.) } \\
1867 \text { oct- } 1868 \text { mar } \\
\text { (1vol.) } \\
1869-1873 \text { (6 vols.) }\end{array}$ \\
\hline $\begin{array}{l}\text { Título } \\
\text { Subtítulo }\end{array}$ & $\begin{array}{l}\text { La Ilustración de la infancia } \\
\text { Revista tipo-autógrafo de educación y } \\
\text { empleo }\end{array}$ & $\begin{array}{l}1877- \\
1879\end{array}$ & $\begin{array}{l}1877-1878 \\
\text { (1 vol.) }\end{array}$ \\
\hline $\begin{array}{l}\text { Título } \\
\text { Subtítulo }\end{array}$ & $\begin{array}{l}\text { La Niñez } \\
\text { Revista de educación y recreo }\end{array}$ & $\begin{array}{l}1879- \\
1882\end{array}$ & $\begin{array}{l}1879-\text { Jun } 1881 \text { ( } 1 \\
\text { vol.) } \\
1882 \text { (4 vols.) }\end{array}$ \\
\hline
\end{tabular}

Tabla 1. Publicaciones periódicas infantiles en la Biblioteca del Museo del Romanticismo

El Museo de familias, creado y dirigido en Barcelona por Antonio Bergnes de las Casas, se editó entre 1838 y 1841 , y sus principales temas fueron literatura, ciencias, economía, educación, historia, religión y viajes. Se editaron 32 números en cuarto mayor con periodicidad mensual, 32 páginas y dos columnas; en la biblioteca del Museo se conservan 20 encuadernados en tres volúmenes. El Mentor de la infancia, fundado por Manuel de Santa Ana, salió entre 1843 y 1845 con formato cuarto, 16 páginas y escasas ilustraciones. La biblioteca dispone de un volumen correspondiente al año 1845.

El Faro de la niñez fue editado por la Sociedad de Socorros Mutuos de Instrucción Pública. Sus propietarios fueron Manuel Vallejo y Gregorio Urbano Dargallo, que ejerció de director. Sacó seis números al mes entre 1849 y 1851, en formato folio y 8 páginas en dos columnas. En febrero de 1850 fue comprado por Manuel Alonso Díez. Se conservan dos volúmenes entre octubre de 1849 y junio de 1851 .

La Ilustración de la infancia se editó en Madrid por Nicolás González, dirigido en dos etapas por Carlos Luis de Cuenca y Alfonso Enrique Ollero. La periodicidad fue semanal, con 8 páginas a dos columnas, aunque en 1878 salió tres veces al mes. Su formato era cuarto y objetivo "Aficionar a los niños a la literatura, proporcionándoles pasatiempo y diversión". En la biblioteca del Museo se conservan los años 1877 y 1878.

La Semaine des enfants se editó en París entre 1857 y 1875 , en formato cuarto mayor con periodicidad semanal y 8 páginas. No se conocen centros de 
documentación en España donde se conserven ejemplares, excepto un volumen de 1857 en la Biblioteca Nacional. La Bibliothèque Nationale de París dispone de una colección completa, y en la del Museo del Romanticismo se localizan siete años: 1861, y 1868 a 1873. La Niñez fue dirigida por Manuel Osorio y Bernard en formato cuarto mayor con diseño a dos columnas. La biblioteca conserva cinco volúmenes fechados entre enero de 1879 y diciembre de 1882 (faltan los ejemplares entre julio y diciembre de 1881).

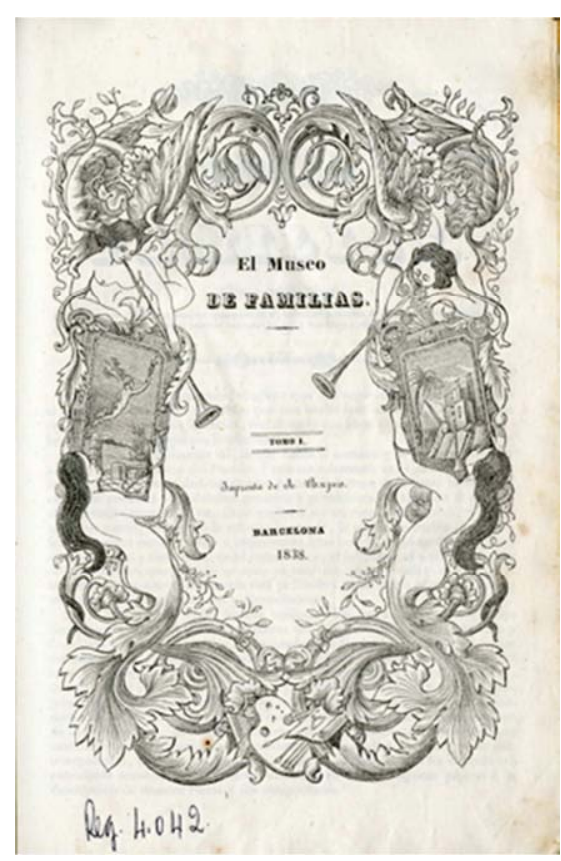

Figura 1. Museo de familias, 1838

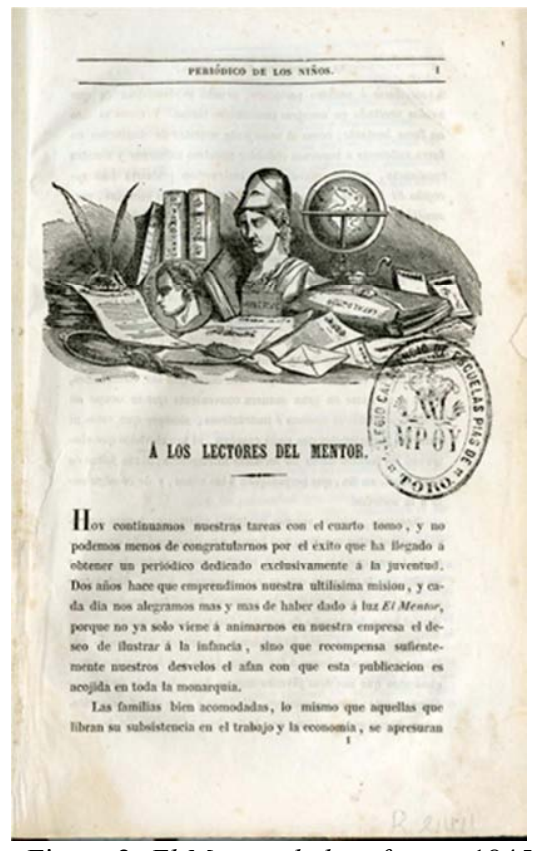

Figura 2. El Mentor de la infancia, 1845

\section{RESULTADOS}

Los resultados de la investigación nos permiten aportar información sobre los aspectos formales, los periodos de edición de las publicaciones, las principales materias de los textos, los autores de relevancia (escritores e ilustradores), los temas de las ilustraciones y la cantidad de las mismas en relación a los textos.

\subsection{Periodos de edición}

Por lo que respecta al periodo de edición (Figura 3) se observan dos claramente diferenciados. El primero entre 1838 y 1851, en pleno desarrollo del Romanticismo, con El Museo de familias, El Mentor de la infancia y El Faro de la niñez, y el segundo durante la Restauración entre 1877 y 1882, con La Ilustración de la infancia 
y La Niñez. La franja central se completa con los ejemplares del periódico francés $L a$ Semaine des enfants, cuyo diseño y formato son similares a El Museo de familias.

\begin{tabular}{|c|c|c|c|c|c|c|c|c|c|c|c|}
\hline PERIÓDICOS/AÑOS & $\begin{array}{l}1830 \\
1835 \\
\end{array}$ & $\begin{array}{l}1835 \\
1840 \\
\end{array}$ & $\begin{array}{l}1840 \\
1845 \\
\end{array}$ & $\begin{array}{l}1845 \\
1850 \\
\end{array}$ & $\begin{array}{l}1850 \\
1855 \\
\end{array}$ & $\begin{array}{l}1855 \\
1860 \\
\end{array}$ & $\begin{array}{l}1860 \\
1865 \\
\end{array}$ & $\begin{array}{l}1865 \\
1870 \\
\end{array}$ & $\begin{array}{l}1870 \\
1875 \\
\end{array}$ & $\begin{array}{l}1875 \\
1880 \\
\end{array}$ & $\begin{array}{l}1880 \\
1885 \\
\end{array}$ \\
\hline Museo de familias & & & & & & & & & & & \\
\hline El Mentor de la infancia & & & & & & & & & & & \\
\hline El Faro de la niñez & & & & & & & & & & & \\
\hline La Semaine des enfants. & & & & & & & & & & & \\
\hline La ilustración de la infancia & & & & & & & & & & & \\
\hline La Niñez & & & & & & & & & & & \\
\hline
\end{tabular}

Figura 3. Periodos de publicación

\subsection{Contenidos: materias generales y específicas}

Los términos empleados para describir las publicaciones periódicas en el siglo XIX fueron fundamentalmente: panorama, museo, faro e ilustración, entendidos como el "compendio de obras que se exhiben o se muestran para destacar su carácter informativo universal en una evidente intención de globalizar" (Sánchez-Vigil, 2008). En el caso que nos ocupa encontramos dichos términos en Museo de familias, El Faro de la niñez y La Ilustración de la infancia. Con respecto a las materias que se deducen a partir de los títulos y subtítulos, resultan nueve términos (Tabla 2). Todas las publicaciones orientaron sus contenidos hacia la enseñanza, con intención moralizante y con un trasfondo religioso. Solo los periódicos La Semaine y La Niñez hicieron en su presentación referencia específica al entretenimiento.

\begin{tabular}{|l|l|}
\hline \multicolumn{1}{|c|}{ MATERIAS } & \multicolumn{1}{c|}{ PUBLICACIONES PERIÓDICAS } \\
\hline Diversión & La Semaine des enfants, La Niñez, \\
\hline Educación & $\begin{array}{l}\text { El Faro de la niñez, La Mustración de la infancia, } \\
\text { La Niñez, La Semaine des enfants }\end{array}$ \\
\hline Empleo & La llustración de la infancia \\
\hline Familia & El Mentor de la infancia, Museo de familias \\
\hline Ilustración & La llustración de la infancia \\
\hline Imágenes & La Semaine des enfants \\
\hline Infancia & $\begin{array}{l}\text { El Faro de la niñez, El Mentor de la infancia, La Niñez, } \\
\text { La llustración de la infancia, La Semaine des enfants }\end{array}$ \\
\hline Juventud & El Mentor de la infancia \\
\hline Lectura & La Semaine des enfants \\
\hline
\end{tabular}

Tabla 2. Materias generales según los títulos y subtitulos 


\subsection{Textos y autoría}

El número de colaboradores fue elevado en todos los casos, con excepción de $E l$ Mentor y El Museo de las familias. Son significativos La Ilustración de la infancia y La Niñez, con más de 50 autores en tres años de existencia. En El Museo de familias la mayoría de los textos se dedicaron a la literatura y a la historia, si bien firmaron muy pocos escritores: José Mor de Fuentes, Antoni Rovira Trías, Antoni Fargas Soler y Joaquín María Bover. El Mentor de la infancia reservó mayor espacio a las ciencias, el arte, la literatura y la religión, y también se echa en falta la autoría en gran parte de los artículos, con excepción de M. I. de Lerena, algunas siglas (F.D.M. y S.D.), y el seudónimo Tenorio, habitual al pie de las fábulas. El Faro de la niñez combinó literatura con ciencias y geografía, y contó con una veintena de colaboradores, entre ellos: Antonio Alvera Degrás, Jacinto Arguello Rosado, M. A. Berzosa, José Manuel Bonilla, Pascual Fernández Baeza, Rafael García Santisteban, José Guerrero, Felipe Antonio Macías, Manuel Joaquín Pascual, Ramón Rodríguez de la Barrera, Manuel Rodríguez Escobar, R. Rubio Murillas, Adriano Antonio Suárez y Santiago Torres.

La Ilustración de la infancia, además de la literatura, cultivó biografías y ciencias. Firmaron más de cuarenta autores, entre ellos varias mujeres y prestigiosos literatos románticos: Julia Asensi, Ramón de Campoamor, Carlos Luis de Cuenca, Josefa Esteve, Antonio Fernández Grilo, Juan Nicasio Gallego, Blanca Gasso y Ortiz, María de la Concepción Gimeno, Ángela Grossi, Juan Eugenio Hartzenbusch, Ángel Lasso de la Vega, Enriqueta Lozano de Vilches, Rafael Luna, Ramón de Mesonero Romanos, Alfonso E. Ollero, María del Carmen Prat, José María Quadrado, José Sánchez de Neira, Ricardo Sepúlveda o María del Pilar Sinués.

También La Niñez tuvo gran número de colaboradores, con cerca de ochenta especialistas, entre ellos: Luis Álvarez Alvistur, Julián Bastinos, Patrocinio Biedma, Julia de la Cámara, J. del Castillo y Soriano, Carlos Croizart, Joaquín García Balmaseda, Celso Gomis, Juan Eugenio Hartzenbusch, Juan de Macías Juliá, Ventura Mayorga, Julio Nombela, Joaquín Olmedilla y Puig, Manuel Ossorio y Bernard, Emilia Pardo Bazán, Manuel Joaquín Pascual, María de la Peña, Manuel Genaro Rentero, Ramón Segade Campoamor, Enrique Segovia Rocaberti, Ricardo Sepulveda, María del Pilar Sinués, Livinio Stuyck, E. Thuillier y Mariano del Todo.

El periódico francés La Semaine des enfants tuvo tres temas preferentes: literatura, historia y religión. Los colaboradores fueron más de 200, entre ellos: F. E. Adam, L. D’ Altemont, L. Bailleul, Maurice Barr, Comtesse de Bassanville, Madame Bouquet, Ch. Brunet, Emilie Carpentier, Frederick B. Chateubriand, Maurice Cherveix, Juliette Cuvillier-Fleury, Frederic Delacroix, Adrienne Depuichault, Charles Deulin, Mme O. Dupin, Paul Durand, La Fontaine, Marie Guerrier de Haupt; A. Guizot, M. D. Hauterive, León Laujon, Nelly Lieutier, F. M. Luzel, X. Marmier, Florence Martigue, Mayne-Reid, Edouard Mohl, Adolphe Orain, Camile Périer, Paul Saunière, Alfred Seguin, Comtesse de Ségur, Madame de Stolz, Ch. de Travanet, Marie Vincent y Madame Witt. 


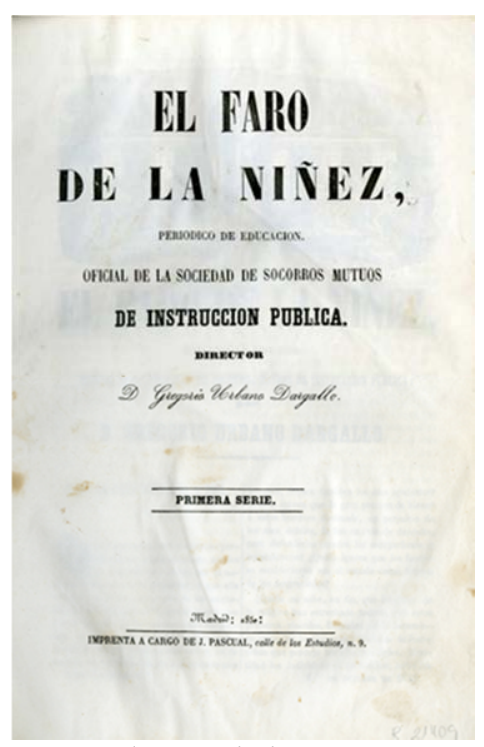

Figura 4. El Faro de la niñez, 1850

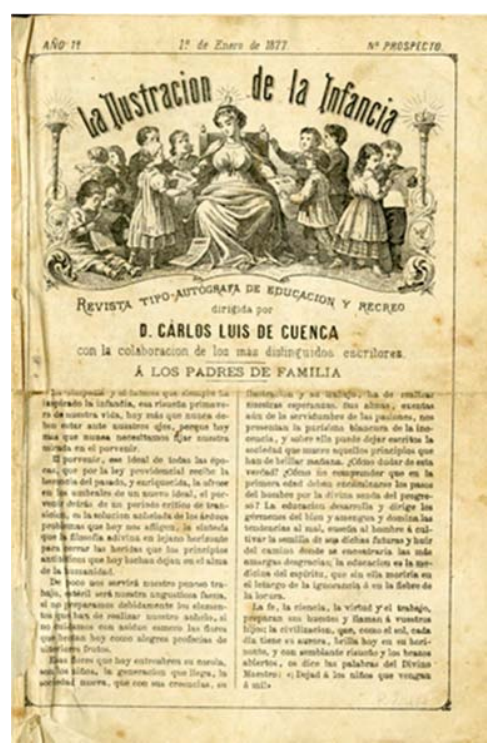

Figura 5. La Ilustración de la infancia, 1877

\subsection{Ilustraciones e ilustradores}

En las 8462 páginas de los 20 volúmenes que suman las seis publicaciones, se reproducen 3322 ilustraciones libres de derechos de autor y por tanto de gran valor para los documentalistas gráficos y los bancos de imágenes especializados. Los formatos medios son de un cuarto de página, por lo que resultan 830 páginas de ilustraciones, equivalentes al $9,80 \%$ del total (Tabla 3 y Figura 6 ).

\begin{tabular}{|l|r|r|r|r|r|r|}
\hline \multicolumn{1}{|c|}{ PUBLICACIONES } & \multicolumn{1}{|c|}{ VotS. } & \multicolumn{1}{c|}{$\begin{array}{c}\text { PÁGS. } \\
\text { TOTALES }\end{array}$} & $\begin{array}{l}\text { LLUSTRAC. } \\
\text { TOTALES }\end{array}$ & $\begin{array}{c}\text { PAGS. DE } \\
\text { LLUSTRAC, }\end{array}$ & $\begin{array}{r}\% \\
\text { TEXTO }\end{array}$ & $\begin{array}{r}\% \\
\text { LLUSTRAC. }\end{array}$ \\
\hline Museo de familias & 3 & 1280 & 168 & 42 & 96,72 & 3,28 \\
\hline El Mentor de la infancia & 1 & 336 & 25 & 6 & 98,22 & 1,78 \\
\hline El Faro de la niñez & 2 & 967 & 307 & 77 & 92,04 & 7,96 \\
\hline La Semaine des enfants. & 8 & 3288 & 1913 & 478 & 85,50 & 14,50 \\
\hline La Ilustración de la infancia & 1 & 792 & 368 & 92 & 89,39 & 11,61 \\
\hline La Niñez & 5 & 1799 & 541 & 135 & 92,50 & 7,50 \\
\hline \multicolumn{1}{r|}{ TOTAL } & 20 & 8462 & 3322 & 830 & 90,20 & 9,80 \\
\hline
\end{tabular}

Tabla 3. Número de ilustraciones y relación con el texto 


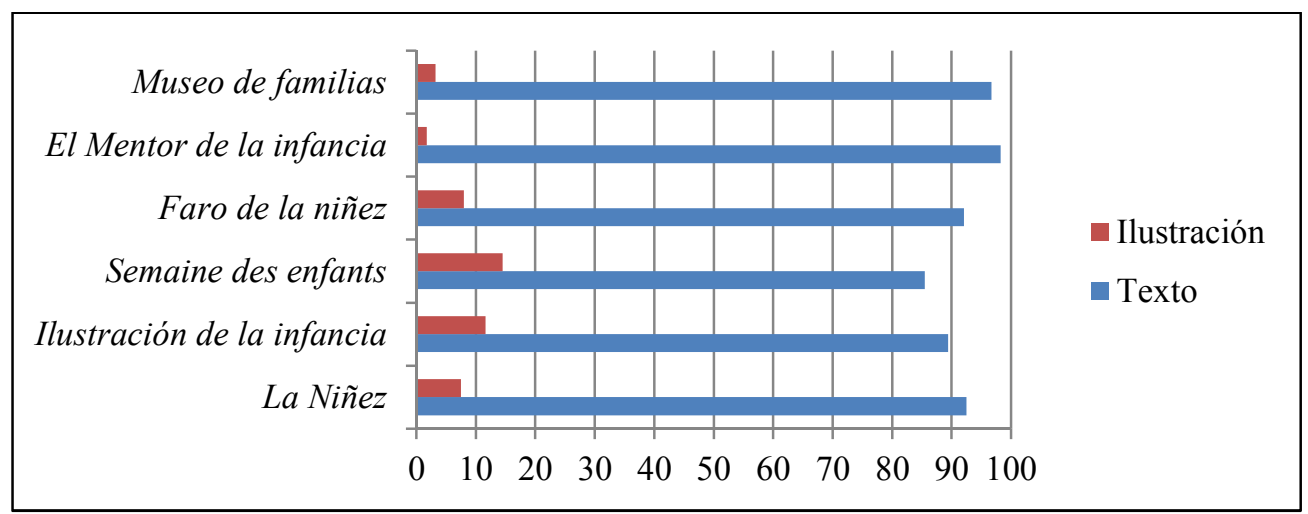

Figura 6. Porcentaje de texto e ilustraciones en cada publicación

De la valoración de los contenidos de las ilustraciones resulta el siguiente listado de materias: biografía, ciencias, educación, geografía, historia y arte, jeroglíficos, literatura, portada y colofones, religión y moral, tipos y costumbres, viajes y zoología. Para elaborarlo, además de la relación con el texto, se ha tenido en cuenta la representación en cada grabado; es el caso de los dibujos de animales, que se han incluido en zoología, o de los tipos populares que ilustran temas literarios, para los que se ha creado un apartado especial ad hoc. Las vistas de ciudades y los paisajes se han incluido en geografía, y se ha considerado un apartado de jeroglíficos por su característica específica.

El Museo de familias suma 168 grabados entre 1838 y 1840, un tercio a página. Predomina la literatura, seguida de historia y arte, geografía y viajes. Los principales dibujantes y grabadores fueron: Miguel Torner, Josep Gaspar, Jaime Batlle, Joan Prats, P. Martínez, Andrew W. Bert Leloir, Antoni Rovira Trías y Edward Wattier. El Mentor de la infancia se ilustró con 25 grabados de media al año, todos sin firma, y en su mayoría dedicados a temas históricos. Destacan los dibujos de juegos firmados por Eusebio Zarza. En El Faro de la niñez los principales temas de ilustración fueron literatura, religión, geografía y ciencias, con 307 grabados. Se encargaron de los dibujos Capuz, Jiménez, Merino, Robles, Urrabieta y Vilaplana, y los principales grabadores fueron Coderch y Murcia. Destacan las imágenes sobre planetas y eclipses (1-30/07/1850), los signos del zodiaco (1/08/1850), y las vistas de ciudades, entre ellas Berlín o Ámsterdam (21/08/1850).

La Ilustración de la infancia sumó 368 ilustraciones en dos años, principalmente sobre literatura, ciencias y biografías. En la página final se incluyeron pasatiempos y patrones para bordar, grabados por F. González. El dibujante oficial fue E. Bolaños, y se publicaron también dibujos y grabados de Capuz, Menéndez, Ortega, Palmaroli, Pellicer, Julián Sala, Severini y Toro. La Niñez reprodujo 541 ilustraciones, con preferencia a la literatura, tipos y costumbres, y religión. El grabado de cabecera lo firmó Múgica, y su principales ilustradores fueron: Bastinos, Bravo, Capuz, 
Carretero, Casanova, Ramón Cortés, Gerard, José Girardent, Não, Pellicer, Perea, G. Phat, Puiggarí, Manuel Sala, Severini, Toro, Urrutia y Vallejo. En el número de mayo de 1880 se publicaron dos dibujos de la Infanta Eulalia de Borbón (niños y paisaje), grabados por José Massi.

La Semaine des enfants dio prioridad en las ilustraciones a literatura, historia, geografías, viajes y ciencia, y fue de las primeras en reproducir imágenes a partir de fotografías, como la vista de Argel según foto de M. Moullin (22/01/1861). La relación de dibujantes supera el centenar, destacando: E. Berard, Bertall, D. A. Borget, B. Castell, H. Catenaci, E. F. David, E. Deschamps, Gustave Doré, L. Duyont, Gustave Hand, G. Jundl, Eugene Ladreit, G. Path, A. Lançon, W. J. Linton, E. Mettois, F. Morten, Jules Pelcog, A. Pessin, R. Pibaraud, Ch. Rod, L. Rouyer, F. Shilippoteaus y W. Thomas. Sobresale Gustave Doré, cuyas obras fueron grabadas por Pannemaker. Otros grabadores habituales fueron: H. Anelay, Belhatte et Chevauchet, L. Chapon, C. Chazal, E. Deschamps, Eustaque Dorsay, J. Gauchard, A. Jourdain, C. Laplante, Lebreton, G. Pericón, F. Pierdon, D. Thiebault, Trichon y Henri Valentin.

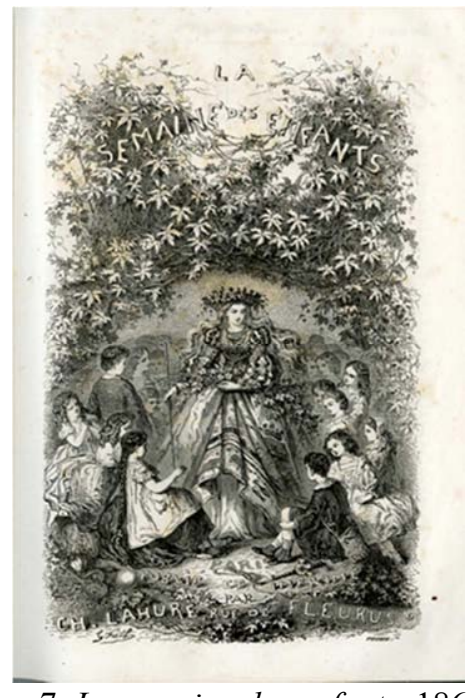

Figura 7. La semaine des enfants, 1861

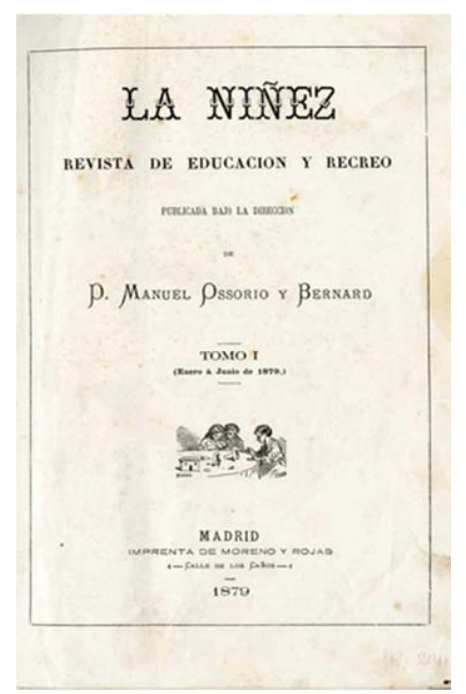

Figura 8. La Niñez, 1879

La valoración de las ilustraciones y su cuantificación (Tabla 4) da como resultado que los textos literarios fueron los más ilustrados (1.231 grabados), seguidos por tipos y costumbres, biografías, religión y moral, ciencias e historia y arte. El apartado educación es el menos ilustrado (98), seguido de viajes (104), que aunque podría haberse añadido a geografía se ha optado por mantenerlo al tratarse de una materia recurrente en el periodo romántico. 


\begin{tabular}{|c|c|c|c|c|c|c|c|}
\hline MATERIAS & $\begin{array}{l}\text { MUSEO DE } \\
\text { FAMILIAS }\end{array}$ & $\begin{array}{c}\text { MENTOR } \\
\text { INFANCI } \\
\mathrm{A}\end{array}$ & $\begin{array}{l}\text { FARO } \\
\text { NIÑEZ }\end{array}$ & $\begin{array}{l}\text { ILUSTRAC. } \\
\text { INFANCIA }\end{array}$ & $\begin{array}{l}\text { SEMAINE } \\
\text { ENFANTS }\end{array}$ & $\begin{array}{c}\text { LA } \\
\text { NIÑEZ }\end{array}$ & TOTAL \\
\hline Biografía & 18 & 2 & 21 & 80 & 44 & 36 & 201 \\
\hline Ciencias & 15 & - & 36 & 58 & 71 & 23 & 203 \\
\hline Educación & - & 2 & 11 & 32 & 36 & 17 & 98 \\
\hline Geografía & 21 & - & 34 & 20 & 106 & 31 & 212 \\
\hline Historia y Arte & 26 & 9 & 5 & 18 & 126 & 38 & 222 \\
\hline Jeroglíficos & - & - & - & 5 & 12 & 5 & 22 \\
\hline Literatura & 44 & 4 & 89 & 92 & 873 & 129 & 1.231 \\
\hline Portada y colofones & 15 & 5 & 28 & 2 & 40 & 63 & 153 \\
\hline Religión y Moral & 8 & - & 48 & 10 & 75 & 56 & 197 \\
\hline Tipos y costumbres & 8 & 2 & 15 & 19 & 355 & 129 & 528 \\
\hline Viajes & - & 1 & 6 & 1 & 96 & - & 104 \\
\hline Zoología & 13 & - & 14 & 31 & 79 & 14 & 151 \\
\hline TOTAL & 168 & 25 & 307 & 368 & 1.913 & 541 & 3.322 \\
\hline
\end{tabular}

Tabla 4. Materias y número de las ilustraciones

\section{CONCLUSIONES}

Cabe señalar que con las seis publicaciones periódicas infantiles del Museo del Romanticismo puede realizarse un seguimiento de este tipo de prensa a lo largo del siglo XIX. En cuanto a los contenidos, se constata que son fundamentales para estudiar materias como literatura, educación, moral y costumbres. Se concluye además que los principales temas en cuanto al texto son literatura, historia y ciencias, seguidos de geografía y religión. Escribieron más de 200 autores, muchos de ellos de gran prestigio en la literatura española, como Juan Nicasio Gallego, Campoamor, Mesonero Romanos, Hartzenbusch o Pardo Bazán.

Las ilustraciones constituyen una fuente documental gráfica de excepción, tanto por los temas como por la calidad. Se han contabilizado 3322 grabados para una docena de materias, destacando por cantidad literatura, tipos y costumbres, biografía, ciencias, geografía, historia y religión. Estas ilustraciones, aun teniendo un rol complementario en ciertos casos y con un espacio no superior al $10 \%$ del total de páginas, son fundamentales para la creación de un banco de imágenes libre de derechos de autor. Se han recuperado asimismo los nombres de un centenar de ilustradores y grabadores. 


\section{BIBLIOGRAFÍA}

ALTARRIBA, Antonio (2001). La España del tebeo. La historia española de 1940 a 2000. Madrid: Espasa.

AMEIJEIRAS, Cristina (1991). "Publicaciones periódicas infantiles y juveniles: dossier". Educación y Biblioteca, Año 3, n. 14, pp. 47-56.

BIMUs (2012). Primeras Jornadas sobre Bibliotecas de Museos: nuevos medios y nuevos públicos. Madrid: Ministerio de Educación y Cultura.

CHECA GODOY, Antonio (2002). Historia de la prensa pedagógica en España. Sevilla: Universidad de Sevilla.

CHIVELET, Mercedes (2009). La prensa infantil en España: desde el siglo XVIII hasta nuestros días. Madrid: Fundación SM.

CUADRADO, Jesús (2000). De la historieta y su uso, 1873-2000 (2 vols.). Madrid: Sinsentido y Fundación Germán Sánchez Ruipérez.

DORADO-PÉREZ, Paloma (2012). "La digitalización en el Museo del Romanticismo. Ayudas convocadas por el Ministerio de Educación, Cultura y Deporte”. En: Primeras Jornadas de Bibliotecas de Museos, pp. 267-272.

ESCARPIT, Denise (1986). La literatura infantil y juvenil en Europa. Panorama histórico. México: Fondo de Cultura Económica.

MARTÍN, Antonio (1967). "Apuntes para una historia de los tebeos "Los periódicos para la infancia (1833-1917)”. Revista Educación, 197, pp. 98-106.

MARTÍNEZ-COMECHE, Juan-Antonio; CACHEDA Seijo, F. (2011). "Information Retrieval Systems Evaluation: Learning and Teaching Process". En: Efthimiadis, E. [et al.] (eds.). Teaching and Learning in Information Retrieval. Berlin: Springer-Verlag, pp. 123-136.

MENÉNDEZ-ROBLES, M.L. (2006). El Marqués de la Vega Inclán y los orígenes del turismo en España. Madrid: Ministerio Industria y Turismo.

Museo del Romanticismo. http://museoromanticismo.mcu.es/colecciones

PALENQUE, Marta (1998). "Prensa y creación literaria durante la Restauración, 1874-1902", en García de la Concha, Víctor (coordinador). Historia de la literatura española, s. XIX (II), pp. 59-72.

SÁNCHEZ-VIGIL, Juan-Miguel (2008). Revistas ilustradas en España. Del Romanticismo a la guerra civil. Gijón: Trea.

TRENC-BALLESTER, Eliseo; editor (1996). La prensa ilustrada en España. Las ilustraciones (1850-1920). Montpellier: Universidad. 